\title{
Comparison of choroidal hyperreflective spots on optical coherence tomography images between both eyes of normal subjects
}

\author{
Young Ho Kim^, Jaeryung $\mathrm{Oh}^{\wedge}$ \\ Department of Ophthalmology, Korea University College of Medicine, Seoul, Korea
}

Contributions: (I) Conception and design: J Oh; (II) Administrative support: Both authors; (III) Provision of study materials or patients: J Oh; (IV) Collection and assembly of data: Both authors; (V) Data analysis and interpretation: Both authors; (VI) Manuscript writing: Both authors; (VII) Final approval of manuscript: Both authors.

Correspondence to: Jaeryung Oh, MD. Department of Ophthalmology, Korea University College of Medicine, 73 Goryeodae-ro Sungbuk-ku, Seoul, Korea. Email: ojr4991@korea.ac.kr; ojr4991@yahoo.co.kr.

Background: Advancement of optical coherence tomography (OCT) technology allows for better in vivo visualization of the choroidal architecture, which comprises vessels and stroma. However, most OCT studies using image binarization methods have focused only on choroidal vessels represented by dark pixels. This study aimed to compare the distribution of choroidal hyperreflective spots on swept-source OCT (SS-OCT) images between both eyes of normal subjects.

Methods: In this observational comparative study, we included SS-OCT images of healthy subjects, which were prospectively obtained to compare images among the devices. SS-OCT images acquired using PLEX Elite 9000 and DRI-OCT Triton were analyzed. En-face OCT images were obtained at five different depth positions of the inner choroid at the macula. The mean reflectivity of the choroidal slabs, the number, total area, and circularity of hyperreflective spots were quantitatively compared between the devices and between both eyes of the same subjects.

Results: In 30 eyes of 15 healthy subjects, the mean reflectivity of the choroidal slabs varied with the scan depth on both devices $(\mathrm{P}<0.001$ and $\mathrm{P}<0.001)$. Hyperreflective spots were similarly distributed in the images from both devices, but at different depths. The number and area of hyperreflective spots in the second and third layers of the DRI-OCT Triton were positively correlated with those in the fourth and fifth layers of the PLEX Elite 9000, respectively (all $\mathrm{P}<0.05$ ). The intraclass correlation coefficients (ICC) for the area of hyperreflective spots were excellent for the third slab of the DRI-OCT and the fifth slab of the PLEX Elite (ICC $=0.798$; 95\% CI, -0.576-0.904). The number and area of hyperreflective spots were correlated between both eyes in the third, fourth and fifth layers on DRI-OCT Triton (all $\mathrm{P}<0.05$ ) and in the first, second, and fifth layers on PLEX Elite 9000 (all $\mathrm{P}<0.05$ ).

Conclusions: Hyperreflective spots in en-face images from two different SS-OCT devices were similarly observed between both eyes of the same person. The distributions of spots between the two eyes of the same person were correlated. These findings suggest that the distribution of hyperreflective spots on the choroid reflects the choroidal characteristics of the subject.

Keywords: Choriocapillaris; choroidal stroma; choroidal vascularity; hyperreflective foci; swept-source optical coherence tomography (SS-OCT)

^ ORCID: Jaeryung Oh, 0000-0002-1036-6562; Young Ho Kim, 0000-0002-5281-1185. 
Submitted Jun 18, 2021. Accepted for publication Aug 04, 2021.

doi: 10.21037/qims-21-637

View this article at: https://dx.doi.org/10.21037/qims-21-637

\section{Introduction}

The choroid is a vascular coat that supports retinal homeostasis (1-4). Choroidal vessels have been studied under various conditions (5-9) and many chorioretinal diseases are associated with choroidal vascular changes (10-20). The choroid comprises both stroma and vessels $(1,4,11,21)$. With increasing age, the subfoveal choroidal thickness progressively decreases (22) and the thicknesses of Sattler's and Haller's layers and their vascular diameters also decrease (23). The choriocapillaris density also decreases with age (22).

Recent advances in optical coherence tomography (OCT) technology have allowed for better in vivo visualization of the choroidal architecture. Recent OCT studies have used image binarization methods to determine the relative ratios between the vascular or stromal components of the choroid, such as the choroidal vascular index (CVI) (24-28). Agrawal et al. (24) reported that in healthy subjects, CVI was less affected by demographic factors such as age and axial length than choroidal thickness. Breher et al. (27) showed little variation in the CVI across the $10-\mathrm{mm}$ center of the posterior pole, whereas choroidal thickness decreased with increasing eccentricity. Most studies reported decreased luminal and total choroidal areas with increasing age in normal subjects (28-31). Sonoda et al. (28) reported that the stromal area decreased with increasing age, while Ruiz-Medrano et al. (31) reported that it remained stable. Age-related changes in the choroidal vascularity index are controversial $(24,30,32)$. However, most studies have reported that the CVI decreases with increasing axial length. $(24,27,28)$ The ratio of stroma to vessels has been suggested as a key component influencing the choriocapillaris flow and is also involved in the pathogenesis of various chorioretinal diseases (11,33-37). However, few studies have focused on the choroidal stroma and analyzed their characteristics in En face OCT images of normal subjects.

Choroidal stroma has been reported to play a role in agerelated macular degeneration and pachychoroid spectrum diseases in previous studies (11). The choroidal stroma comprises various cells and connective tissue elements that cause variations in the choroid reflectance in the OCT images. These variations in reflectance make it difficult to analyze the choroidal stroma in OCT images (38); thus, the characteristics of the choroidal stroma in normal eyes have not been well determined in vivo. We hypothesized that variations in choroidal reflectance could reflect the choroidal properties of the subjects. In this study, we used two different swept-source OCT (SS-OCT) devices to quantitatively determine hyperreflective spots at various depth positions of the upper choroid and compared the distribution of hyperreflective spots between both eyes of the same subject. We present the following article in accordance with the STROBE reporting checklist (available at https://dx.doi.org/10.21037/qims-21-637).

\section{Methods}

This observational comparative study was a retrospective analysis of prospectively acquired OCT data. Previously, we acquired SS-OCT images of healthy subjects to compare images among various devices (39). Healthy Asian subjects with normal fundus and axial lengths of less than $26.5 \mathrm{~mm}$ were prospectively included from May 2017 to August 2018 after informed consent was obtained from all individual participants.

In this study, data analysis was performed on May 2021. We analyzed SS-OCT images acquired using two different SS-OCT devices (Zeiss PLEX Elite 9000 and Topcon DRI OCT Triton). The OCT images were obtained from the OCT database of our hospital. The Institutional Review Board of Korea University Medical Center approved this study. Informed consent was waived for this study as it was a retrospective review of anonymized image data. All research and data collection were performed in accordance with the tenets of the Declaration of Helsinki (as revised in 2013). Additional information, including age, sex, laterality, and axial length was collected. Axial length was measured using the IOL Master (version 7.3.0.0048, Carl Zeiss Meditec AG, Jena, Germany).

\section{OCT imaging protocol}

OCT images were obtained during the optical coherence tomography angiography (OCTA) scanning protocol. Imaging was performed without pupil dilation using two 
Table 1 Comparisons of two different swept-source optical coherence tomography devices

\begin{tabular}{lcccccc}
\hline Device & Wavelength & $\begin{array}{c}\text { Scan speed } \\
\text { (A-scans/second) }\end{array}$ & $\begin{array}{c}\text { Axial/transverse } \\
\text { resolution }\end{array}$ & Scan area & $\begin{array}{c}\text { Number of A-scans } \\
\text { per B-scan }\end{array}$ & $\begin{array}{c}\text { Number of } \\
\text { repeated B-scans }\end{array}$ \\
\hline DRI OCT Triton & $1,050 \mathrm{~nm}$ & 100,000 & $5 \mu \mathrm{m} / 15 \mu \mathrm{m}$ & $3 \mathrm{~mm} \times 3 \mathrm{~mm}$ & 320 & 4 \\
PLEX Elite 9000 & $1,040-1,060 \mathrm{~nm}$ & 100,000 & $5 \mu \mathrm{m} / 12 \mu \mathrm{m}$ & $3 \mathrm{~mm} \times 3 \mathrm{~mm}$ & 300 & OCTARA \\
\hline
\end{tabular}

OCTARA, optical coherence tomography angiography ratio analysis; OMAG, optical microangiography. Data sourced from Yun C, Nam KT, Park S, Hwang SY, Oh J. Features of the choriocapillaris on four different optical coherence tomography angiography devices. Int Ophthalmol. 2020;40(2):325-333.
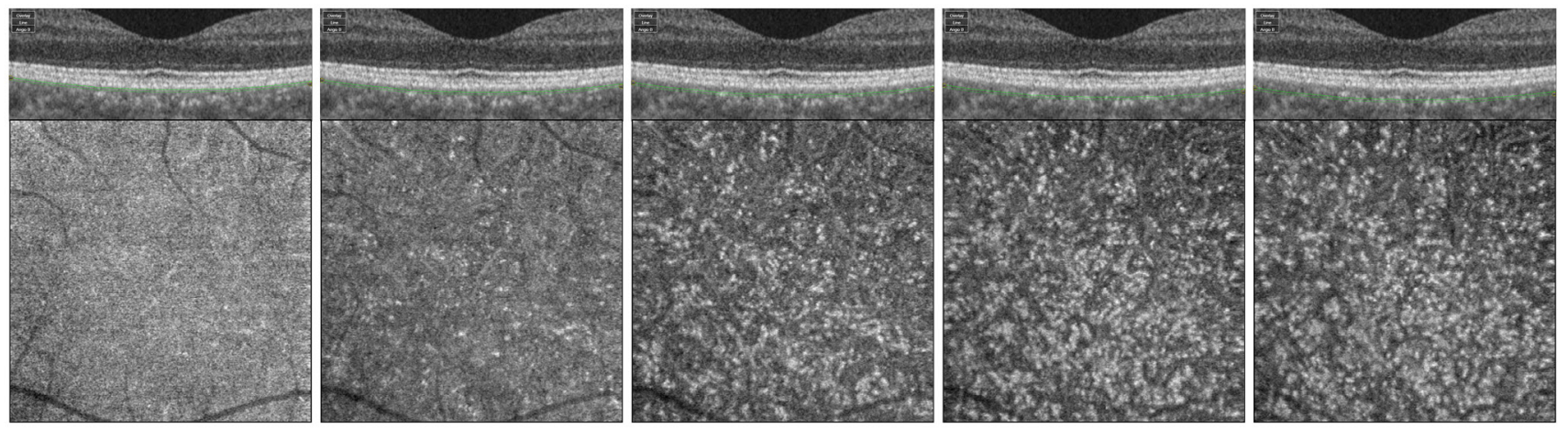

Figure 1 Five en face swept-source optical coherence tomography images at different depth positions. Five $3 \mathrm{~mm} \times 3 \mathrm{~mm}$ En face slabs centered on the fovea with a $10-\mu \mathrm{m}$ thickness were obtained at different depth positions. The first, second, third, fourth, and fifth slabs (from left to right) were taken between 0 and $10.4 \mu \mathrm{m}, 10.4$ and $20.8 \mu \mathrm{m}, 20.8$ and $31.2 \mu \mathrm{m}, 31.2$ and $41.6 \mu \mathrm{m}$, and 41.6 and $52 \mu \mathrm{m}$ below the Bruch's membrane using the DRI OCT Triton device. Green lines indicate segmentation lines for choroidal slabs.

SS-OCT devices: DRI OCT Triton (version 10.13.003.06, Topcon Corp., Tokyo, Japan) and PLEX Elite 9000 (version 1.6.0.21130, Carl Zeiss Meditec, Inc. Dublin, California, USA). On the DRI OCT, En face SS-OCT images were obtained using a $3 \mathrm{~mm} \times 3 \mathrm{~mm}$ SS-OCTA scanning protocol centered on the fovea. Each B-scan consisted of 320 A-scans and was repeated four times at each position (Table 1). On the PLEX Elite 9000, En face SS-OCT images were obtained using the SS-OCTA scanning protocol, consisting of $300 \mathrm{~A}$-scans with four consecutive B-scans with a $3 \mathrm{~mm} \times 3 \mathrm{~mm}$ pattern centered on the fovea. All OCT scans were performed by a single experienced technician at our hospital. Each subject underwent an OCT scan using two devices on the same day. In a random sequence, the two OCT scans were performed within 15 minutes. After each examination, the images were checked, and those with clearly visible retinal vessels and no artifacts were selected. Automated layer segmentation was conducted using the built-in software of each SS-OCT device. Only high-quality images without any artifact and segmentation error were analyzed in this study.

\section{En face OCT images}

En face OCT images were obtained as previously described, with modifications of the previous report (40). Five choroidal layer slabs at different depth positions from the Bruch's membrane (BM), each with a 10- $\mu \mathrm{m}$ thickness were obtained for each device: first $(0-10 \mu \mathrm{m}$ below the $\mathrm{BM})$, second (10-20 $\mu \mathrm{m}$ below the BM), third (20-30 $\mu \mathrm{m}$ below the BM), fourth $(30-40 \mu \mathrm{m}$ below the BM), and fifth $(40-50 \mu \mathrm{m}$ below the BM) choroidal layer slabs, which represented the upper choroidal layers (Figure 1). We determined the position and thickness of each slab using the built-in software of each device. The upper and lower boundaries of each slab were manually adjusted. As the choriocapillaris is located directly beneath the $\mathrm{BM}$ and has a thickness of approximately $10 \mu \mathrm{m}$ in normal subjects $(22,40,41)$, we selected five choroidal layer slabs with adjustment of depth positions in each device as follows. On the DRI OCT Triton device, the inner and outer segmentation lines could not be accurately adjusted by $10-\mu \mathrm{m}$, so they were instead adjusted by $10.4-\mu \mathrm{m}$ intervals. To obtain the first choroidal 

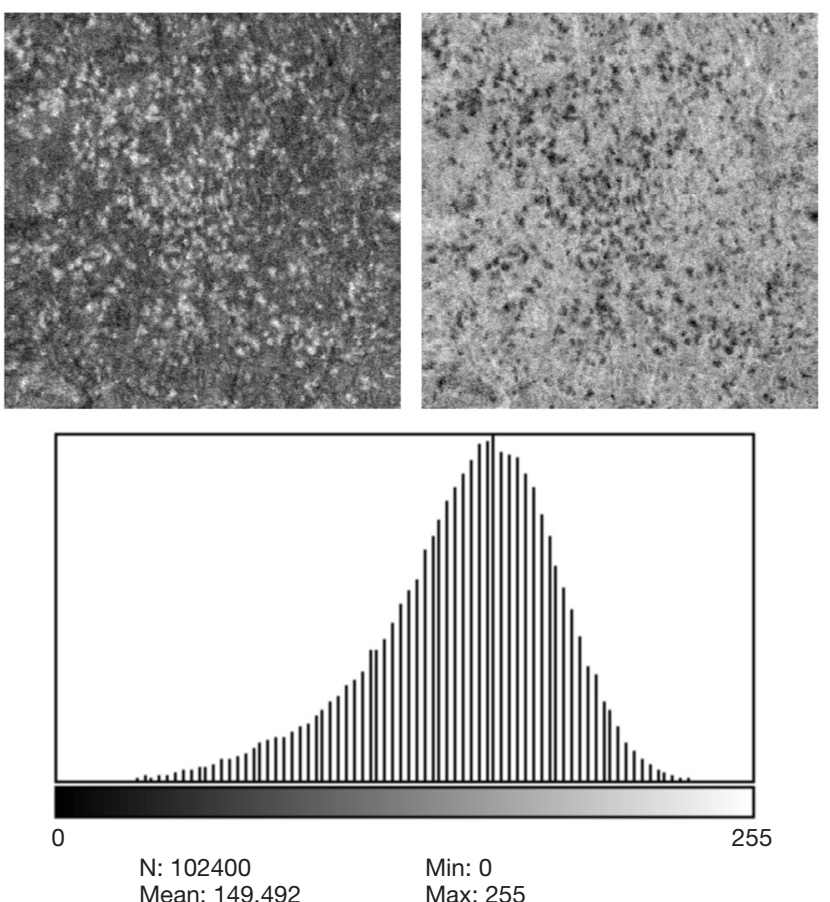

StdDev: $33.714 \quad$ Mode: 160(4082)

Value: $28 \quad$ Count: 0
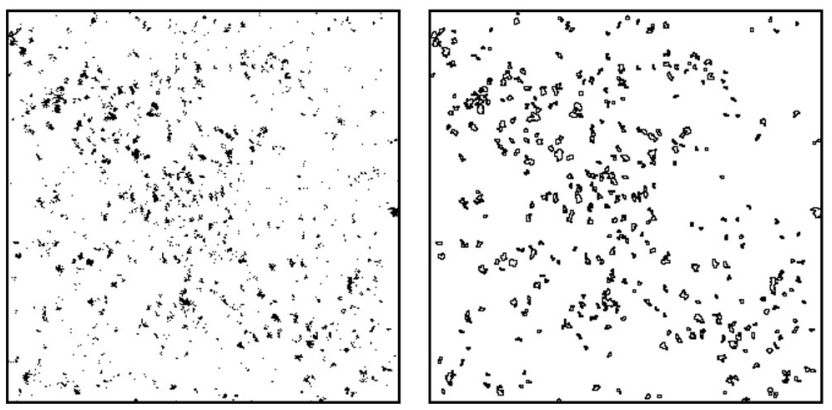

Figure 2 Measurements of reflectivity and hyperreflective spots of En face swept-source optical coherence tomography (OCT) images. After uploading the En face OCT image in ImageJ (top left), the image was edited to reverse black/white and converted to 8-bits (top right). Thereafter, the figure histogram was analyzed (middle). The image was binarized with a threshold level set at two standard deviations below the mean of the reflectivity from the histogram (bottom left). The number, total area, average size, and circularity of hyperreflective spots were measured using the analyzed particle tool to trace the boundary on the image containing the hyperreflective spots over $314 \mu^{2}$ (bottom right). layer slab of the En face image of DRI OCT Triton, we used the default setting of the device for the choriocapillaris, which has inner and outer segmentation lines at $0 \mu \mathrm{m}$ and $10.4 \mu \mathrm{m}$ below the BM. Subsequent slabs were obtained at 10.4- $\mu \mathrm{m}$ intervals with manual adjustment of inner and outer segmentation lines, with the second, third, fourth, and fifth slabs obtained between $10.4 \mu \mathrm{m}$ and $20.8 \mu \mathrm{m}$, $20.8 \mu \mathrm{m}$ and $31.2 \mu \mathrm{m}, 31.2 \mu \mathrm{m}$ and $41.6 \mu \mathrm{m}$, and $41.6 \mu \mathrm{m}$ and $52 \mu \mathrm{m}$ below the BM, respectively. To obtain the first choroidal layer slab of the En face image on the PLEX Elite 9000 device, the inner and outer segmentation lines for the retinal pigment epithelium (RPE) fit were moved to 0 $\mu \mathrm{m}$ and $10 \mu \mathrm{m}$ below the BM. The second, third, fourth, and fifth slabs were taken between 10 and $20 \mu \mathrm{m}, 20$ and $30 \mu \mathrm{m}, 30$ and $40 \mu \mathrm{m}$, and 40 and $50 \mu \mathrm{m}$ below the BM, respectively. Five En face choroidal slab images of each device were exported and used for imaging analysis.

\section{Measurement of choroidal reflectivity and byperreflective spots}

After uploading the En face OCT images in ImageJ (http:// imagej.nih.gov/ij/; provided by the National Institutes of Health in the public domain), they were edited to reverse black/white and converted to 8-bit images (Figure 2). The scale was set from pixels to micrometers, and the figure histograms were analyzed. To remove the insignificant area and better visualize the hyperreflective spots, the reflectivity threshold level was set at two SDs below the mean reflectivity of the image histogram, and only spots below this threshold level were analyzed. Considering that clustered small spots appear to be connected to each other and to prevent these clustered spots mistakenly identified as a large spot, we used the watershed function (42). The hyperreflective spots were measured using the analyzed particle tool to trace the boundary of the image containing the hyperreflective foci. As SS-OCT provides a transverse resolution of $20 \mu \mathrm{m}$ (43), we defined the minimum diameter and area of hyperreflective spots as $20 \mu \mathrm{m}$ and $314 \mu^{2}$, respectively, to prevent counting noise signals as hyperreflective spots. Any particle with an area $<314 \mu^{2}$ 
on ImageJ was not included in the analysis. The number, total area, average size, and circularity of the hyperreflective spots were calculated and compared between the two devices and between both eyes of the same subjects.

\section{Statistical analysis}

Statistical analyses were performed using IBM SPSS Statistics for Windows, version 20.0 (IBM Corp., Armonk, NY, USA). All data are expressed as median with interquartile ranges (IQRs). Correlations were analyzed using Spearman's correlation coefficient $(\rho)$. The baseline characteristics were compared using the Mann-Whitney $\mathrm{U}$ test for continuous variables. The differences between the layers were analyzed using the Friedman test. Then, Dunn-Bonferroni post hoc multiple comparisons were performed between the different variable combinations. The differences between the right and left eyes of the same subjects were analyzed using the Wilcoxon signedrank test. Results were considered statistically significant at $\mathrm{P}<0.05$. Intraclass correlation coefficients (ICCs) were used to analyze the agreement between the devices, which were defined as poor for ICC $<0.40$, fair for $0.4-0.6$, good for $0.6-0.75$, and excellent for $0.75-1.00$ (44).

\section{Results}

\section{General characteristics}

This study included 30 eyes from 15 healthy volunteers (7 males and 8 females) with a median age of 33.0 (range, 29-45) years. The median axial lengths of the right and left eyes were 25.16 (IQR, 24.70-25.52) $\mathrm{mm}$ and 25.26 (IQR, 24.83-25.41) mm, respectively $(\mathrm{P}=0.983)$. In both devices, the mean reflectivity of the choroidal layer slab at all depth positions did not differ between females and males (all $\mathrm{P}>0.05$ ), except for the fourth slab of the PLEX Elite $9000(\mathrm{P}=0.029)$. There were no differences in the mean reflectivity between both eyes in all choroidal layer slabs (all $\mathrm{P}>0.05$ ).

\section{Correlation of byperreflective spots with age and axial length}

The number of hyperreflective spots was not correlated with age in all choroidal slabs of bilateral eyes on both OCT instruments (all $\mathrm{P}>0.05$ ), except the fourth slab of right eye on DRI OCT Triton device $(\rho=-0.537 \mathrm{P}=0.039)$. The total area of hyperreflective spots were negatively correlated with age in the third slab of the right eye $(\rho=-0.535, \mathrm{P}=0.040)$ and in the fourth choroidal layer slab of both eyes on the DRI OCT Triton device $(\rho=-0.557, \mathrm{P}=0.031$ and $\rho=-0.598$, $\mathrm{P}=0.018$ ), but had no correlation with age in all other slabs of bilateral eyes on both OCT instruments (all $\mathrm{P}>0.05$ ). The number of hyperreflective spots also did not show any correlation with axial length in all choroidal slabs of bilateral eyes on either OCT instrument (all $\mathrm{P}>0.05$ ), except the fourth slab of the right eye on DRI OCT Triton device $(\rho=-0.537 \mathrm{P}=0.039)$. The total area of hyperreflective spots were negatively correlated with axial length in the fifth slab of left eye $(\rho=-0.601, P=0.018)$, but had no correlation with axial length in all other slabs of bilateral eyes on both OCT instruments (all $\mathrm{P}>0.05$ ). The correlation of the mean reflectivity and distribution of hyperreflective spots with age and axial length in 30 eyes of 15 normal participants are summarized in Tables S1,S2.

\section{Variations of mean reflectivity and distributions of byperreflective spots at five upper choroidal layer slabs}

The mean reflectivity of each slab varied with the depth position of the slabs on both devices $(\mathrm{P}<0.001$ and $\mathrm{P}<0.001)$ (Table 2). Dunn-Bonferroni post hoc multiple comparisons showed that the mean reflectivity of En face images in the first choroidal layer slab was the lowest on both SS-OCT devices (Table S3). The mean reflectivity was the greatest in the second choroidal layer slab on the DRI OCT Triton device, but this value did not differ significantly from that of the third choroidal layer slab $(\mathrm{P}=0.338)$ On the PLEX Elite 9000 device, the third, fourth, and fifth choroidal layer slabs had higher reflectivity than the first and second choroidal layer slabs (all $\mathrm{P}<0.010$ ). Hyperreflective spots were observed at all depth positions in the choroidal slabs (Figure 3). On the DRI OCT Triton device, hyperreflective spots were most frequently observed in the third layer of the choroid (all $\mathrm{P}<0.05$ ). The total area of hyperreflective spots tended to be the greatest in the third choroidal slab, but the value did not differ significantly from those in the second and fifth slabs $(\mathrm{P}>0.999$ and $\mathrm{P}=0.222$, respectively). On the PLEX Elite 9000 device, the number and total area of hyperreflective spots were the greatest in the fifth layer, but the values did not differ significantly from those in the fourth choroidal layer slab $(\mathrm{P}=0.724$ and $\mathrm{P}>0.999$, respectively). 
Table 2 Comparisons of reflectivity of the choroidal stroma and distributions of hyperreflective spots between En face slab images obtained at five different depth positions of the upper choroid

\begin{tabular}{|c|c|c|c|c|c|c|}
\hline & First layer & Second layer & Third layer & Fourth layer & Fifth layer & $P$ value \\
\hline Reflectivity & $133.5(126.5-143.4)$ & $154.8(150.3-157.5)$ & $149.9(148.1-152.7)$ & $148.6(142.6-151.1)$ & $145.4(142.2-148.4)$ & $<0.001^{*}$ \\
\hline \multicolumn{7}{|c|}{ Hyperreflective spots } \\
\hline Number & $115.0(97.3-156.5)$ & 247.5 (216.5-277.0) & $294.5(273.0-330.0)$ & $275.0(237.5-307.8)$ & $263.0(236.3-287.5)$ & $<0.001^{*}$ \\
\hline Circularity & $0.674(0.658-0.701)$ & $0.644(0.622-0.656)$ & $0.649(0.628-0.664)$ & $0.657(0.638-0.665)$ & $0.641(0.631-0.664)$ & $<0.001^{*}$ \\
\hline $\begin{array}{l}\text { Average size, } \\
\mu \mathrm{m}^{2}\end{array}$ & $\begin{array}{c}589.1 \\
(526.5-664.8)\end{array}$ & $\begin{array}{c}1,000.3 \\
(918.1-1,103.7)\end{array}$ & $\begin{array}{c}938.7 \\
(820.1-999.1)\end{array}$ & $\begin{array}{c}868.4 \\
(741.1-917.1)\end{array}$ & $\begin{array}{c}873.1 \\
(797.1-972.9)\end{array}$ & $<0.001^{*}$ \\
\hline \multicolumn{7}{|l|}{ PLEX Elite 9000} \\
\hline Number & $42.5(35.0-63.0)$ & $76.5(39.8-120.3)$ & $143.0(107.8-159.0)$ & $207.5(162.8-240.5)$ & 262.5 (212.5-278.8) & $<0.001^{*}$ \\
\hline $\begin{array}{l}\text { Total area, } \\
\mu \mathrm{m}^{2}\end{array}$ & $\begin{array}{c}20,050.0 \\
(16,600.0-31,825.0)\end{array}$ & $\begin{array}{c}40,050.0 \\
(18,400.0-81,200.0)\end{array}$ & $\begin{array}{c}105,350.0 \\
(74,500.0-142,250.0)\end{array}$ & $\begin{array}{c}206,450.0 \\
(123,550.0-233,000.0)\end{array}$ & $\begin{array}{c}228,000.0 \\
(171,875.0-271,350.0)\end{array}$ & $<0.001^{*}$ \\
\hline Circularity & $0.775(0.723-0.801)$ & $0.749(0.673-0.771)$ & $0.659(0.640-0.692)$ & $0.661(0.639-0.693)$ & $0.662(0.649-0.686)$ & $<0.001^{*}$ \\
\hline $\begin{array}{l}\text { Average size, } \\
\mu m^{2}\end{array}$ & $482.0(460.5-516.1)$ & $532.1(483.0-650.6)$ & $721.3(606.4-885.8)$ & 889.7 (766.8-1008.7) & 889.7 (807.7-966.2) & $<0.001^{*}$ \\
\hline
\end{tabular}

Data are expressed as median (interquartile range). *, $\mathrm{P}$ values using the Friedman test were statistically significant at $\mathrm{P}<0.05$.

\section{Comparisons of byperreflective spots between devices}

Hyperreflective spots were similarly distributed in images between devices, but at different depth positions of the choroidal layer slabs (Figure 4). The number of hyperreflective spots in the second and third slabs of the DRI OCT Triton device were positively correlated with those in the fourth $(\rho=0.378, P=0.040)$ and fifth $(\rho=0.505$, $\mathrm{P}=0.004)$ slabs of the PLEX Elite 9000 device, respectively. (Figure 5). The total area of hyperreflective spots for the second and third slabs of the DRI OCT Triton were also positively correlated with those for the fourth $(\rho=0.370$, $\mathrm{P}=0.044)$ and fifth $(\rho=0.700, \mathrm{P}<0.001)$ slabs of the PLEX Elite 9000, respectively. The fourth slab of the DRI OCT Triton and the fifth slab of PLEX Elite 9000 had also positive correlation for the total area of hyperreflective spots $(\rho=0.411, \mathrm{P}=0.024)$. Bland-Altman plots showed fair to good agreement of the measurements of hyperreflective spots between the DRI OCT Triton and PLEX Elite 9000 devices (Figure 6). The ICCs were fair to excellent between the third slab of the DRI OCT Triton and the fifth slab of the PLEX Elite 9000 in all measurements for hyperreflective spots, including the number, total area, and circularity (Table 3). We observed excellent agreement in the total area of the hyperreflective spots between the third slab of the DRI OCT Triton and the fifth slab of the PLEX Elite 9000 [ICC $=0.798,95 \%$ confidence interval (CI): 0.576-0.904]. The fourth slab of the PLEX Elite 9000 device had fair agreement with the second slab of the DRI OCT Triton in the number and total area of hyperreflective spots $(\mathrm{ICC}=0.507,95 \% \mathrm{CI}:-0.037-0.765$; ICC $=0.526$, 95\% CI: 0.003-0.774, respectively).

\section{Comparisons of hyperreflective spots between eyes in individual subjects}

For the DRI OCT Triton device, the mean reflectivity of the slabs was correlated between the right and left eyes only in the third and fourth slabs $(\rho=0.704, P=0.003 ; \rho=0.750$, $\mathrm{P}=0.001$ ), while the PLEX Elite 9000 device showed correlation at all four layers (all $\mathrm{P}<0.05$ ) except for the fourth layer $(\mathrm{P}=0.187)$ (Table 4). In the DRI OCT Triton 


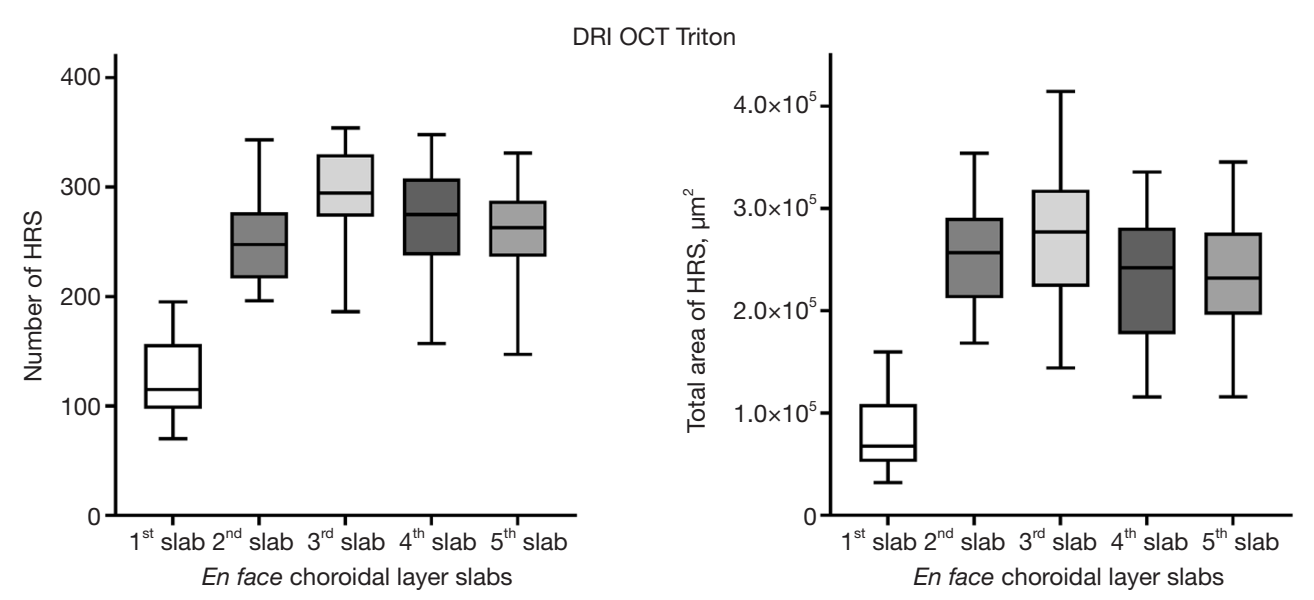

PLEX elite 9000
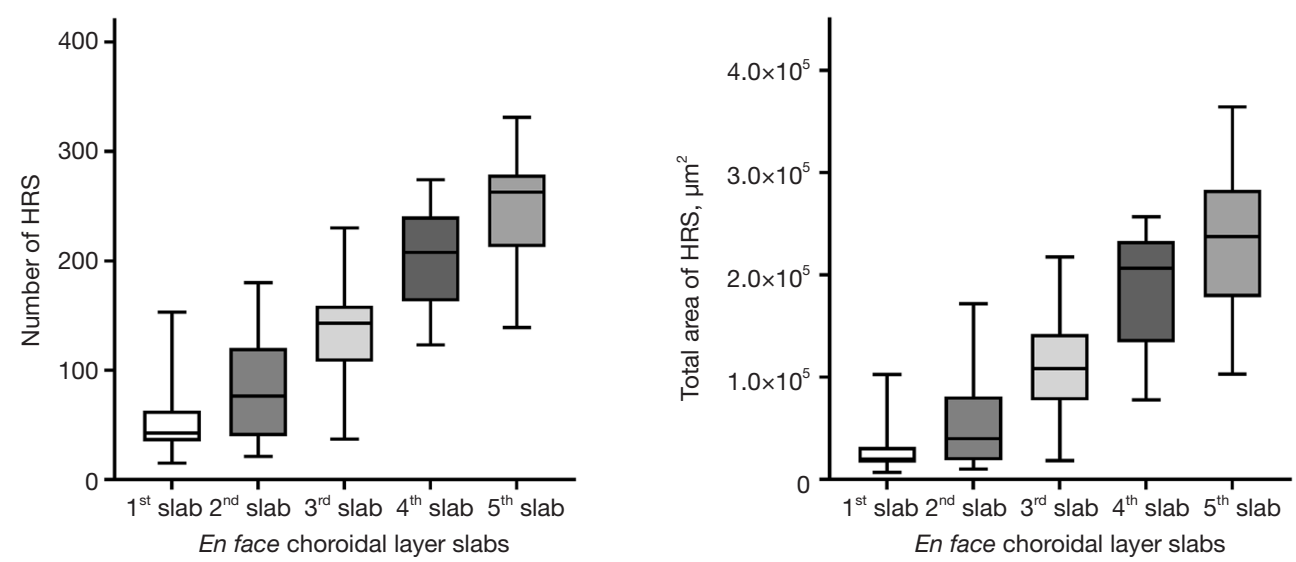

Figure 3 Distribution of the number (left column) and total area (right column) of hyperreflective spots on En face choroidal layer slab images obtained at five different depths of the upper choroid with the DRI OCT Triton (upper row) and PLEX Elite 9000 devices (lower row). HRS, hyperreflective spots.

device, the number of hyperreflective spots was correlated between both eyes in all slabs (all $\mathrm{P}<0.05$ ) except for the first slab $(\mathrm{P}=0.087)$. The total area of hyperreflective spots was correlated at the third, fourth, and fifth slabs (all $\mathrm{P}<0.05$ ). In the PLEX Elite 9000 device, the number and total area of hyperreflective spots were correlated between both eyes in the first, second, and fifth slabs (all $\mathrm{P}<0.05$ ).

\section{Discussion}

The choroid is present between the sclera and the BM. While the choroid is the vascular bed of the eye that supports homeostasis of the overriding neuroretina, it also contains diverse cell types and connective tissue that form the stroma (1). Previous histological studies have shown that the stroma is populated by various cells and connective tissue elements, including melanocytes, fibroblasts, mast cells, elastic, collagen fibrils, blood vessels, macrophages, dendritic cells, lymphocytes, nonvascular smooth muscle cells, intrinsic neurons, and nerve fibers associated with vessels (45). This characteristic inhomogeneous mixture of various tissues can cause various reflections on OCT imaging. The results of the current study show that the choroidal stroma had various degrees of reflection, which are presented as a histogram with gray scale reflecting the variation in the reflectivity of En face images. This result suggested that the variation of reflectivity in the choroidal stroma can be determined on En face OCT images in normal eyes.

In this study, the mean reflectivity of En face images 

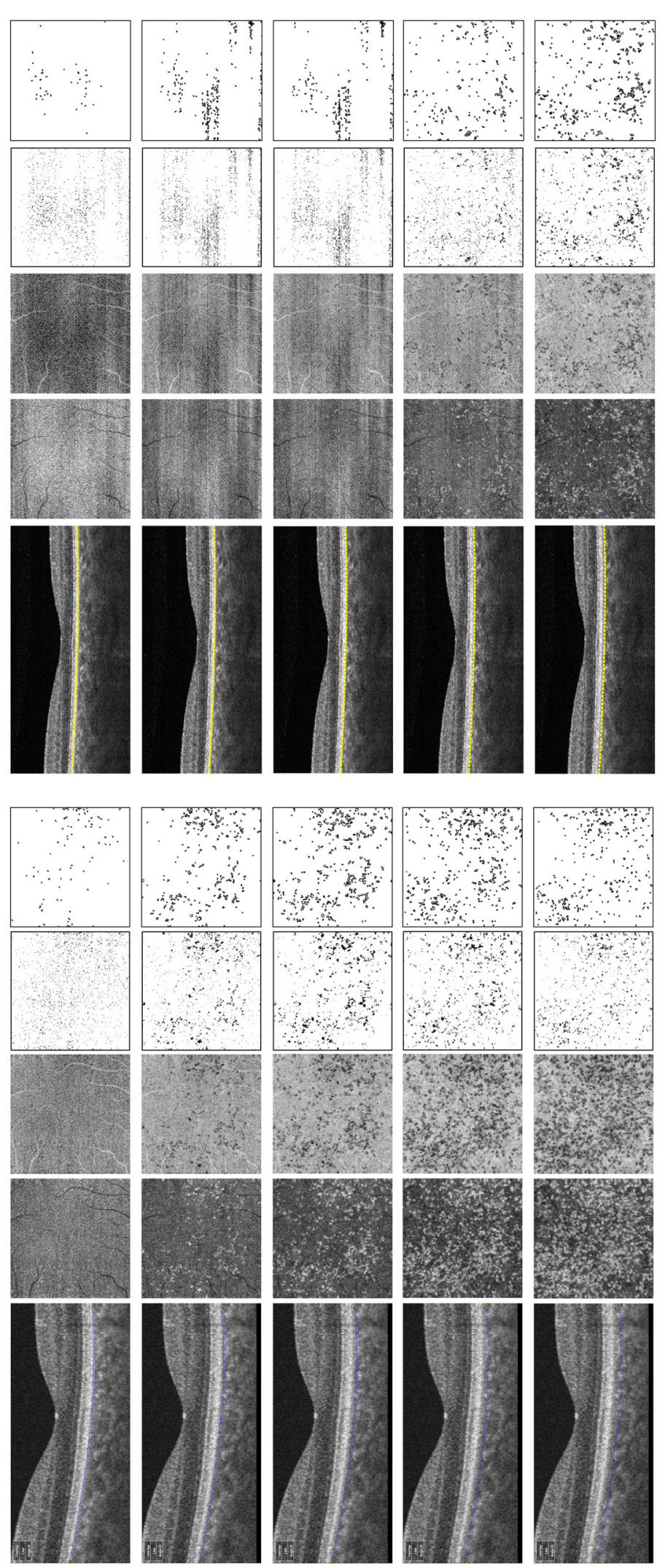

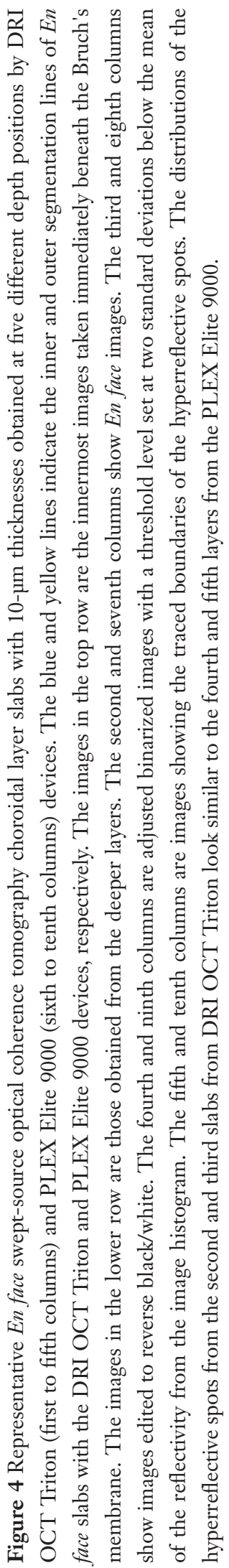




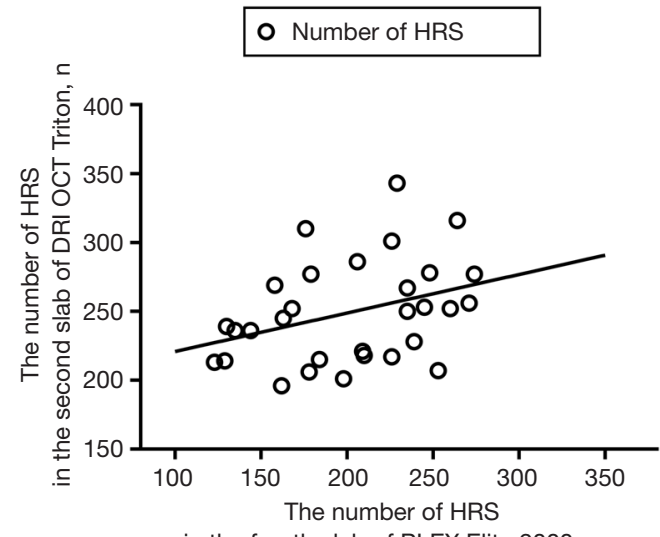

in the fourth slab of PLEX Elite 9000, $n$

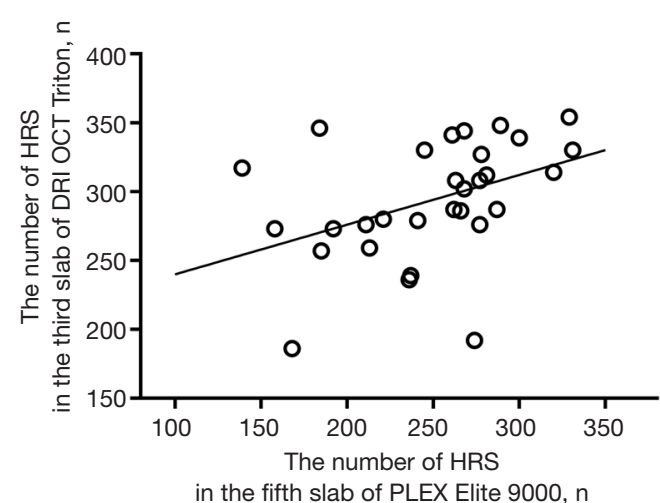

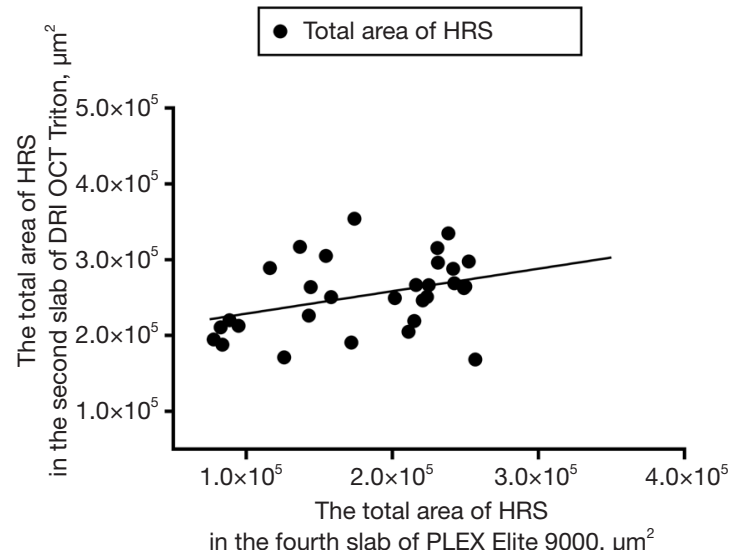

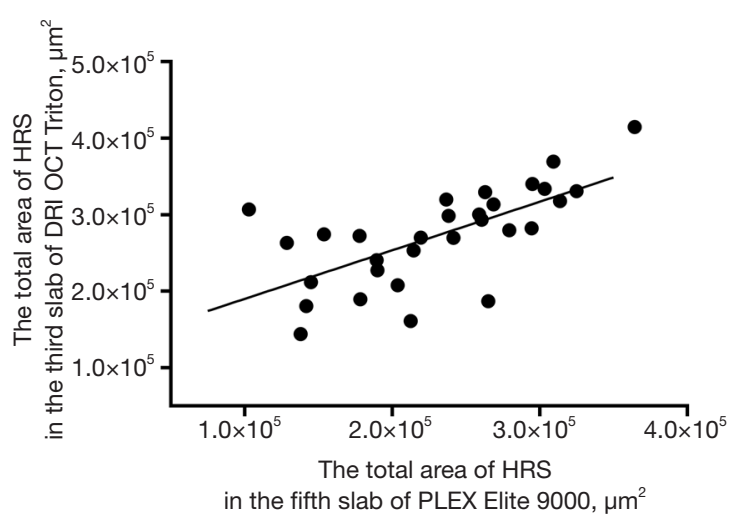

Figure 5 Scatter plots of the number (left column) and total area (right column) of hyperreflective spots between the second (upper row) and third (lower row) choroidal layer slabs of the DRI OCT Triton and the fourth (upper row) and fifth (lower row) slabs of the PLEX Elite 9000, respectively. HRS, hyperreflective spots.

varied throughout all depth positions of the choroidal layer slabs. En face images immediately beneath the BM had the lowest mean reflectivity on both SS-OCT devices. This could be attributed to the fact that the first layer is related to the choriocapillaris, a highly vascularized capillary layer with lower reflectivity than that of the underlying choroidal layer on OCT B-scan $(40,46)$. We also found that some layers had higher reflectivity than others. These findings are consistent with those from OCT B-scan images, in which the upper choroid had higher reflectivity than the deeper choroid. This could be due to the limited penetration depth of the OCT technology. Even with SS-OCT, signals from deeper choroidal structures tend to be weaker than those from the inner choroids $(46,47)$. However, other explanations may also contribute to this observation; for instance, the differences in the ratios of stroma with high reflectivity and vascular cavity with low reflectivity between En face images obtained at different choroidal depths may have resulted in mean reflectivity differences among En face images (40). For example, immediately below the choriocapillaris, the inner choroid may have more stromal components than the middle of the choroid. This may mean that the reflectivity of En face images can be used as a value representing the reflectivity of the choroidal stromal layer at each depth of the choroid. Another possible explanation for the origin of this variation may be the presence of a structure with abnormally high reflectance in specific layers (48-51).

In this study, we defined hyperreflective spots as areas with reflectivity over two SDs of the mean reflectivity of the En face image. Hyperreflective spots are more frequently observed in En face images with higher mean reflectivity than in those with lower mean reflectivity. The finding that the hyperreflective spots are prominent in a certain layer below the BM suggests that the hyperreflective foci reflect a specific component of the choroidal stroma. To investigate 

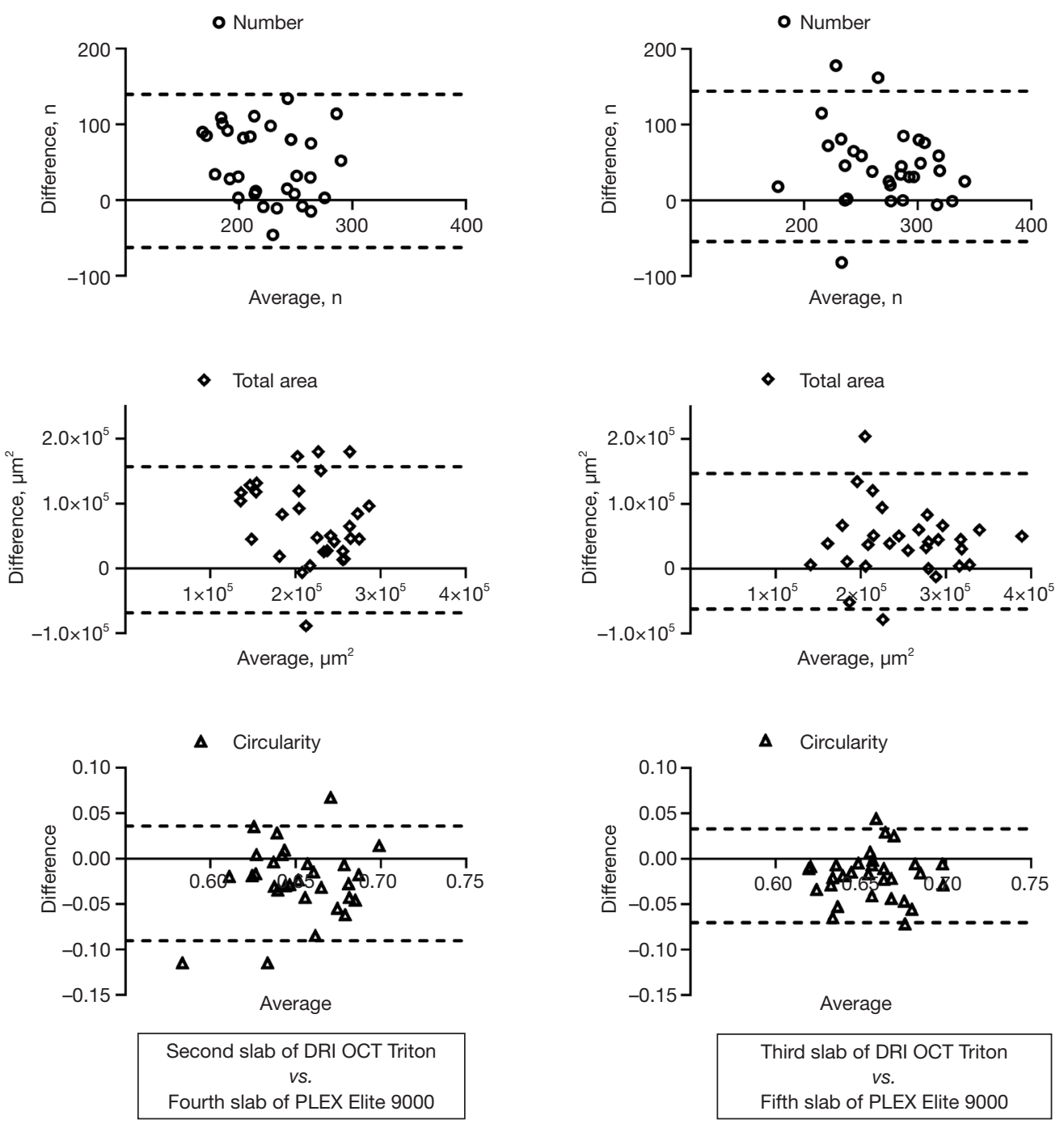

Figure 6 Bland-Altman plots for the number, total area, and circularity of hyperreflective spots. The differences between the second (left column) and third (right column) choroidal layer slabs of the DRI OCT Triton and the fourth (left column) and fifth slabs (right column) of the PLEX Elite 9000 were plotted against their average, respectively. The $95 \%$ limits of agreement are shown as upper (the mean difference plus 1.96 times SD) and lower (the mean difference minus 1.96 times SD) dotted lines.

whether the hyperreflective spots were signal noise or a phenomenon occurring due to the physical characteristics of specific OCT instruments, we compared the distribution of hyperreflective spots between En face images from two different OCT devices in the same subject. We found that the distribution was similar between the En face images obtained from the two different OCT devices. Although the depth positions of slabs below the BM of the En face images differed, the patterns of distribution of the hyperreflective spots were similar between images from the two devices. The number and total area of hyperreflective spots were highest at 20.8-31.2 $\mu \mathrm{m}$ below the BM in the DRI OCT Triton device, but were highest at $40-50 \mu \mathrm{m}$ below the BM in the PLEX Elite 9000 device. This difference may be due to the different algorithms used to segment the BM or RPE between the two OCT devices. It may also originate from the differences in the algorithms used to segment the upper boundary of the choroid (39). In the DRI OCT Triton device, the default setting for the choriocapillaris slab is $0-10.4 \mu \mathrm{m}$ below the BM, compared to $29-40 \mu \mathrm{m}$ below the RPE fit segmentation line in the PLEX Elite 9000 device. While the depth differed between the devices, 


\begin{tabular}{|c|c|c|c|c|c|c|c|c|c|c|}
\hline \multicolumn{2}{|c|}{ Choroidal layer slab } & \multicolumn{9}{|c|}{ Hyperreflective spots } \\
\hline Triton & $\begin{array}{l}\text { PLEX Elite } \\
9000\end{array}$ & ICC & $95 \% \mathrm{Cl}$ & $P$ value & ICC & $95 \% \mathrm{Cl}$ & $P$ value & ICC & $95 \% \mathrm{Cl}$ & $P$ value \\
\hline Second layer & Fourth layer & 0.507 & $-0.037-0.765$ & $0.031^{*}$ & 0.526 & $0.003-0.774$ & $0.025^{\star}$ & 0.432 & $-0.194-0.730$ & 0.067 \\
\hline Fourth layer & Fourth layer & -1.308 & $-3.850-0.099$ & 0.986 & -1.188 & $-3.598--0.042$ & 0.981 & -0.103 & $-1.318-0.475$ & 0.604 \\
\hline Fifth layer & Fourth layer & -1.231 & $-3.687-0.062$ & 0.983 & -0.812 & $-2.807-0.138$ & 0.942 & 0.240 & $-0.597-0.638$ & 0.232 \\
\hline Second layer & Fifth layer & 0.425 & $-0.208-0.726$ & 0.071 & 0.476 & $-0.101-0.751$ & $0.044^{*}$ & 0.349 & $-0.368-0.690$ & 0.127 \\
\hline Third layer & Fifth layer & 0.582 & $0.121-0.801$ & $0.011^{*}$ & 0.798 & $0.576-0.904$ & $<0.001^{*}$ & 0.630 & $0.222-0.824$ & $0.005^{\star}$ \\
\hline
\end{tabular}

${ }^{*}, \mathrm{P}$ values were statistically significant at $\mathrm{P}<0.05$. ICC, intraclass correlation coefficients; $95 \% \mathrm{Cl}, 95 \%$ confidence interval.

the distribution of hyperreflective spots was similar between the En face images. This result suggests that choroidal foci with abnormally high reflectivity exist in normal eyes, even if there are differences between measurement devices.

To elucidate the factors influencing the distribution of hyperreflective spots, we compared the distributions between both eyes of the same subject. We found that both the number and total area of hyperreflective spots was correlated between the bilateral eyes in most slabs of both devices. Although not statistically significant in all choroidal slabs, this correlation was consistently observed in the two different OCT devices. This may suggest that the distribution of hyperreflective spots represents the characteristics of the choroid in each subject. Among the various cells and connective tissues that constitute the choroidal stroma, hyperreflective spots may originate from specific cell groups in the stroma, such as melanocytes, fibroblasts, and macrophages. Although inflammatory cells have also been suggested as a source of hyperreflective spots in diseased eyes (52-54), it is difficult to explain their distribution over a wide range in normal eyes, as observed in the current study. Henle's fiber layer, running perpendicularly against incoming light, is known to exhibit high reflectivity on OCT images (55-57). Similarly, horizontally oriented neural or connective tissues comprising the vascular wall can also induce high reflectivity. However, in this study, the mean circularity of the hyperreflective spots was $0.6-0.7$, and the distribution varied greatly between subjects. These findings suggest that the hyperreflective spots originate from a clump of highly reflective cells or substances. Another possibility is that the prominent hyperreflectivity originates from melanin pigmentation. Previous studies in animals and humans (49-51) suggested melanin pigmentation as a possible origin of hyperreflectivity in the skin, retinal pigment epithelium, and choroid $(58,59)$. The melanin pigment in the choroid absorbs light and limits its reflection. These melanin-rich cells in the choroid may be a source of hyperreflective spots in the choroidal stroma. Yiu et al. (60) showed the effect of uveal melanocytes on choroidal morphology in rhesus macaques and humans on OCT B-scan images. Tsai et al. (59) also showed hyperreflective melanocytes at various skin depths using OCT in patients with junction nevus. The melanocytes in the skin were round in their representative image and appeared to have a shape and size similar to that of the hyperreflective spot in the choroid. They also reported that hyperreflective melanocytes were clearly visible in the En face OCT images at imaging depths of 90 and $110 \mu \mathrm{m}$, but less prominent at imaging depths of $130 \mu \mathrm{m}$, possibly because of the weakening of the signal intensity (59). Weakening of the reflection from the deep layers may prevent clear demarcation of the hyperreflective spots, similar to the findings of our study. These findings support the suggestion that hyperreflective spots may originate from melanin pigmentation. Although many studies have suggested that melanin pigmentation can induce hyperreflective spots in OCT images, further studies are needed to confirm their origin in normal human eyes. 
Table 4 Correlations of mean reflectivity and distribution of hyperreflective spots between right and left eyes of 15 normal subjects

\begin{tabular}{|c|c|c|c|c|}
\hline & \multicolumn{2}{|c|}{ DRI OCT Triton } & \multicolumn{2}{|c|}{ PLEX Elite 9000} \\
\hline \multicolumn{5}{|c|}{ First choroidal layer } \\
\hline Reflectivity & -0.243 & 0.383 & 0.707 & $0.003^{*}$ \\
\hline \multicolumn{5}{|c|}{ Hyperreflective spots } \\
\hline Total area & 0.379 & 0.164 & 0.636 & $0.011^{*}$ \\
\hline \multicolumn{5}{|c|}{ Second choroidal layer } \\
\hline Reflectivity & 0.139 & 0.621 & 0.714 & $0.003^{*}$ \\
\hline \multicolumn{5}{|c|}{ Hyperreflective spots } \\
\hline \multicolumn{5}{|c|}{ Third choroidal layer } \\
\hline Reflectivity & 0.704 & $0.003^{*}$ & 0.575 & $0.025^{\star}$ \\
\hline \multicolumn{5}{|c|}{ Hyperreflective spots } \\
\hline Number & 0.667 & $0.007^{\star}$ & 0.239 & 0.390 \\
\hline Total area & 0.679 & $0.005^{\star}$ & 0.504 & 0.056 \\
\hline \multicolumn{5}{|c|}{ Fourth choroidal layer } \\
\hline Reflectivity & 0.650 & $0.009^{*}$ & 0.361 & 0.187 \\
\hline \multicolumn{5}{|c|}{ Hyperreflective spots } \\
\hline Number & 0.838 & $<0.001^{*}$ & 0.621 & $0.014^{*}$ \\
\hline Total area & 0.796 & $<0.001^{*}$ & 0.607 & $0.016^{\star}$ \\
\hline
\end{tabular}

*, $P$ values using Spearman's correlation analysis were statistically significant at $P<0.05$.

In this study, we found no significant difference in mean reflectivity in En face images of the upper choroid between males and females. We also found that the distributions of hyperreflective spots had no correlation with age and axial length. However, even though they were prospectively collected, a small number of relatively younger participants were enrolled in this study, which might have influenced the results. Moreover, we only included Asian subjects, which may prevent the generalization of our results to other ethnic populations. Further studies on the factors influencing variation in choroidal reflectivity may help us to better understand the clinical significance of hyperreflective spots on the choroid. Another limitation of our study is that we did not analysis the images after image normalization. As the depth of the slab increases, the reflectivity of $E n$ face image could be decreases. Other limitation is that we arbitrary defined the threshold for the hyperreflective spots at two SDs above the mean reflectivity. However, all En face OCT images showed a unimodal distribution and a symmetric or slightly right-skewed distribution in 
the histogram analysis. All histograms had absolute values of skewness and kurtosis less than 1.0. In addition, we did not consider the axial length in image analysis, nor did we consider the magnification effect, caused by axial length differences of the participants. Although we used a $3 \mathrm{~mm}$ $\times 3 \mathrm{~mm}$ scan in this study, it is thought that the differences in axial length may cause a slight difference in image size. However, since we only used a narrow range in the center of the macula, the bias would have limited effect on the outcomes.

In conclusion, choroidal reflectivity varied throughout the choroidal depths. The distributions of hyperreflective spots in En face images were similar between En face images from two different SS-OCT devices, and the distributions were also correlated between both eyes of the same subject. These findings suggest that the distribution of hyperreflective spots on En face images represents the characteristics of the choroid of each subject.

\section{Acknowledgments}

Funding: This work was supported by the Korea Medical Device Development Fund grant funded by the Korean government (the Ministry of Science and ICT, the Ministry of Trade, Industry and Energy, the Ministry of Health \& Welfare, the Ministry of Food and Drug Safety) [Project Number: 1711137942, KMDF_PR_20200901_0026-02].

\section{Footnote}

Reporting Checklist: The authors have completed the STROBE reporting checklist. Available at https://dx.doi. org/10.21037/qims-21-637

Conflicts of Interest: Both authors have completed the ICMJE uniform disclosure form (available at https:// dx.doi.org/10.21037/qims-21-637). The authors report that this work was supported by the Korea Medical Device Development Fund grant funded by the Korea government (the Ministry of Science and ICT, the Ministry of Trade, Industry and Energy, the Ministry of Health \& Welfare, the Ministry of Food and Drug Safety) [Project Number: 1711137942, KMDF_PR_20200901_0026-02]. Both authors have no other conflicts of interest to declare.

Ethical Statement: The authors are accountable for all aspects of the work in ensuring that questions related to the accuracy or integrity of any part of the work are appropriately investigated and resolved. This study was conducted in accordance with the Declaration of Helsinki (as revised in 2013). The study was approved by the Institutional Review Board of Korea University Medical Center, and the requirement for individual consent for this retrospective analysis was waived.

Open Access Statement: This is an Open Access article distributed in accordance with the Creative Commons Attribution-NonCommercial-NoDerivs 4.0 International License (CC BY-NC-ND 4.0), which permits the noncommercial replication and distribution of the article with the strict proviso that no changes or edits are made and the original work is properly cited (including links to both the formal publication through the relevant DOI and the license). See: https://creativecommons.org/licenses/by-nc-nd/4.0/.

\section{References}

1. Nickla DL, Wallman J. The multifunctional choroid. Prog Retin Eye Res 2010;29:144-68.

2. Hayreh SS. Segmental nature of the choroidal vasculature. Br J Ophthalmol 1975;59:631-48.

3. Hayreh SS. In vivo choroidal circulation and its watershed zones. Eye (Lond) 1990;4:273-89.

4. Chirco KR, Sohn EH, Stone EM, Tucker BA, Mullins RF. Structural and molecular changes in the aging choroid: implications for age-related macular degeneration. Eye (Lond) 2017;31:10-25.

5. Sayin N, Kara N, Pekel G, Altinkaynak H. Choroidal thickness changes after dynamic exercise as measured by spectral-domain optical coherence tomography. Indian J Ophthalmol 2015;63:445-50.

6. Usui S, Ikuno Y, Akiba M, Maruko I, Sekiryu T, Nishida K, Iida T. Circadian changes in subfoveal choroidal thickness and the relationship with circulatory factors in healthy subjects. Invest Ophthalmol Vis Sci 2012;53:2300-7.

7. Tan CS, Ouyang Y, Ruiz H, Sadda SR. Diurnal variation of choroidal thickness in normal, healthy subjects measured by spectral domain optical coherence tomography. Invest Ophthalmol Vis Sci 2012;53:261-6.

8. Sizmaz S, Küçükerdönmez C, Pinarci EY, Karalezli A, Canan H, Yilmaz G. The effect of smoking on choroidal thickness measured by optical coherence tomography. Br J Ophthalmol 2013;97:601-4.

9. Ahn J, Ahn SE, Yang KS, Kim SW, Oh J. Effects of a high level of illumination before sleep at night on chorioretinal thickness and ocular biometry. Exp Eye Res 
2017;164:157-67.

10. Cheung CMG, Gan A, Yanagi Y, Wong TY, Spaide R. Association between Choroidal Thickness and Drusen Subtypes in Age-Related Macular Degeneration. Ophthalmol Retina 2018;2:1196-205.

11. Lee M, Lee H, Kim HC, Chung H. Changes in Stromal and Luminal Areas of the Choroid in Pachychoroid Diseases: Insights Into the Pathophysiology of Pachychoroid Diseases. Invest Ophthalmol Vis Sci 2018;59:4896-908.

12. Nassisi M, Tepelus T, Nittala MG, Sadda SR. Choriocapillaris flow impairment predicts the development and enlargement of drusen. Graefes Arch Clin Exp Ophthalmol 2019;257:2079-85.

13. Ting DS, Ng WY, Ng SR, Tan SP, Yeo IY, Mathur R, Chan CM, Tan AC, Tan GS, Wong TY, Cheung CM. Choroidal Thickness Changes in Age-Related Macular Degeneration and Polypoidal Choroidal Vasculopathy: A 12-Month Prospective Study. Am J Ophthalmol 2016;164:128-36.e1.

14. Wang W, Liu S, Qiu Z, He M, Wang L, Li Y, Huang W. Choroidal Thickness in Diabetes and Diabetic Retinopathy: A Swept Source OCT Study. Invest Ophthalmol Vis Sci 2020;61:29.

15. Spaide RF. Disease expression in nonexudative age-related macular degeneration varies with choroidal thickness. Retina 2018;38:708-16.

16. Dansingani KK, Balaratnasingam C, Naysan J, Freund KB. En face Imaging of pachychoroid spectrum disorders with swept-source optical coherence tomography. Retina 2016;36:499-516.

17. Cheung CMG, Lee WK, Koizumi H, Dansingani K, Lai TYY, Freund KB. Pachychoroid disease. Eye (Lond) 2019;33:14-33.

18. Yanagi Y. Pachychoroid disease: a new perspective on exudative maculopathy. Jpn J Ophthalmol 2020;64:323-37.

19. Tavares Ferreira J, Proença R, Alves M, Dias-Santos A, Santos BO, Cunha JP, Papoila AL, Abegão Pinto L. Retina and Choroid of Diabetic Patients Without Observed Retinal Vascular Changes: A Longitudinal Study. Am J Ophthalmol 2017;176:15-25.

20. Borrelli E, Shi Y, Uji A, Balasubramanian S, Nassisi M, Sarraf D, Sadda SR. Topographic Analysis of the Choriocapillaris in Intermediate Age-related Macular Degeneration. Am J Ophthalmol 2018;196:34-43.

21. Branchini LA, Adhi M, Regatieri CV, Nandakumar N, Liu JJ, Laver N, Fujimoto JG, Duker JS. Analysis of choroidal morphologic features and vasculature in healthy eyes using spectral-domain optical coherence tomography. Ophthalmology 2013;120:1901-8.

22. Ramrattan RS, van der Schaft TL, Mooy CM, de Bruijn WC, Mulder PG, de Jong PT. Morphometric analysis of Bruch's membrane, the choriocapillaris, and the choroid in aging. Invest Ophthalmol Vis Sci 1994;35:2857-64.

23. Park KA, Oh SY. An optical coherence tomography-based analysis of choroidal morphologic features and choroidal vascular diameter in children and adults. Am J Ophthalmol 2014;158:716-723.e2.

24. Agrawal R, Gupta P, Tan KA, Cheung CM, Wong TY, Cheng CY. Choroidal vascularity index as a measure of vascular status of the choroid: Measurements in healthy eyes from a population-based study. Sci Rep 2016;6:21090.

25. Agrawal R, Salman M, Tan KA, Karampelas M, Sim DA, Keane PA, Pavesio C. Choroidal Vascularity Index (CVI)-A Novel Optical Coherence Tomography Parameter for Monitoring Patients with Panuveitis? PLoS One 2016;11:e0146344.

26. Fujiwara A, Morizane Y, Hosokawa M, Kimura S, Kumase F, Shiode Y, Doi S, Hirano M, Toshima S, Hosogi M, Shiraga F. Factors Affecting Choroidal Vascular Density in Normal Eyes: Quantification Using En face SweptSource Optical Coherence Tomography. Am J Ophthalmol 2016;170:1-9.

27. Breher K, Terry L, Bower T, Wahl S. Choroidal Biomarkers: A Repeatability and Topographical Comparison of Choroidal Thickness and Choroidal Vascularity Index in Healthy Eyes. Transl Vis Sci Technol 2020;9:8.

28. Sonoda S, Sakamoto T, Yamashita T, Uchino E, Kawano H, Yoshihara N, Terasaki H, Shirasawa M, Tomita M, Ishibashi T. Luminal and stromal areas of choroid determined by binarization method of optical coherence tomographic images. Am J Ophthalmol 2015;159:11231131.e1.

29. Goud A, Singh SR, Sahoo NK, Rasheed MA, Vupparaboina KK, Ankireddy S, Lupidi M, Chhablani J. New Insights on Choroidal Vascularity: A Comprehensive Topographic Approach. Invest Ophthalmol Vis Sci 2019;60:3563-9.

30. Nivison-Smith L, Khandelwal N, Tong J, Mahajan S, Kalloniatis M, Agrawal R. Normal aging changes in the choroidal angioarchitecture of the macula. Sci Rep 2020;10:10810.

31. Ruiz-Medrano J, Ruiz-Moreno JM, Goud A, Vupparaboina KK, Jana S, Chhablani J. AGE-Related changes in choroidal vascular density of healthy subjects 
based on image binarization of swept-source optical coherence tomography. Retina 2018;38:508-15.

32. Zhou H, Dai Y, Shi Y, Russell JF, Lyu C, Noorikolouri J, Feuer WJ, Chu Z, Zhang Q, de Sisternes L, Durbin MK, Gregori G, Rosenfeld PJ, Wang RK. Age-Related Changes in Choroidal Thickness and the Volume of Vessels and Stroma Using Swept-Source OCT and Fully Automated Algorithms. Ophthalmol Retina 2020;4:204-15.

33. Corvi F, Souied EH, Capuano V, Costanzo E, Benatti L, Querques L, Bandello F, Querques G. Choroidal structure in eyes with drusen and reticular pseudodrusen determined by binarisation of optical coherence tomographic images. Br J Ophthalmol 2017;101:348-52.

34. Keenan TD, Klein B, Agrón E, Chew EY, Cukras CA, Wong WT. Choroidal thickness and vascularity vary with disease severity and subretinal drusenoid deposit presence in nonadvanced age-related macular degeneration. Retina 2020;40:632-42.

35. Aribas YK, Hondur AM, Tezel TH. Choroidal vascularity index and choriocapillary changes in retinal vein occlusions. Graefes Arch Clin Exp Ophthalmol 2020;258:2389-97.

36. Bakthavatsalam M, Ng DS, Lai FH, Tang FY, Brelén ME, Tsang CW, Lai TY, Cheung CY. Choroidal structures in polypoidal choroidal vasculopathy, neovascular age-related maculopathy, and healthy eyes determined by binarization of swept source optical coherence tomographic images. Graefes Arch Clin Exp Ophthalmol 2017;25 5:935-43.

37. Kim M, Ha MJ, Choi SY, Park YH. Choroidal vascularity index in type-2 diabetes analyzed by swept-source optical coherence tomography. Sci Rep 2018;8:70.

38. Chandrasekera E, Wong EN, Sampson DM, AlonsoCaneiro D, Chen FK. Posterior Choroidal Stroma Reduces Accuracy of Automated Segmentation of Outer Choroidal Boundary in Swept Source Optical Coherence Tomography. Invest Ophthalmol Vis Sci 2018;59:4404-12.

39. Yun C, Nam KT, Park S, Hwang SY, Oh J. Features of the choriocapillaris on four different optical coherence tomography angiography devices. Int Ophthalmol 2020;40:325-33.

40. Byon I, Nassisi M, Borrelli E, Sadda SR. Impact of Slab Selection on Quantification of Choriocapillaris Flow Deficits by Optical Coherence Tomography Angiography. Am J Ophthalmol 2019;208:397-405.

41. Almeida DR, Zhang L, Chin EK, Mullins RF, Kucukevcilioglu M, Critser DB, Sonka M, Stone EM, Folk JC, Abràmoff MD, Russell SR. Comparison of retinal and choriocapillaris thicknesses following sitting to supine transition in healthy individuals and patients with age-related macular degeneration. JAMA Ophthalmol 2015;133:297-303.

42. Wu H, Sekiryu T, Sugano Y, Itagaki K, Kasai A, Shintake H. A modified measuring method to investigate the choriocapillaris flow void of polypoidal choroidal vasculopathy with swept source optical coherence tomography angiography. Quant Imaging Med Surg 2021;11:3146-56.

43. Copete S, Flores-Moreno I, Montero JA, Duker JS, RuizMoreno JM. Direct comparison of spectral-domain and swept-source OCT in the measurement of choroidal thickness in normal eyes. Br J Ophthalmol 2014;98:334-8.

44. Cicchetti DV. Guidelines, criteria, and rules of thumb for evaluating normed and standardized assessment instruments in psychology. Psychological Assessment 1994;6:284-90.

45. Nag TC, Kumari C. Chapter 2 - Electron microscopy of the human choroid. In: Chhablani J, Ruiz-Medrano J, editors. Choroidal disorders. Academic Press; 2017. p. 7-20.

46. Zhang Q, Zheng F, Motulsky EH, Gregori G, Chu Z, Chen CL, Li C, de Sisternes L, Durbin M, Rosenfeld PJ, Wang RK. A Novel Strategy for Quantifying Choriocapillaris Flow Voids Using Swept-Source OCT Angiography. Invest Ophthalmol Vis Sci 2018;59:203-11.

47. Unterhuber A, Povazay B, Hermann B, Sattmann H, Chavez-Pirson A, Drexler W. In vivo retinal optical coherence tomography at $1040 \mathrm{~nm}$ - enhanced penetration into the choroid. Opt Express 2005;13:3252-8.

48. Weiter JJ, Delori FC, Wing GL, Fitch KA. Retinal pigment epithelial lipofuscin and melanin and choroidal melanin in human eyes. Invest Ophthalmol Vis Sci 1986;27:145-52.

49. Baumann B, Schirmer J, Rauscher S, Fialová S, Glösmann M, Augustin M, Pircher M, Gröger M, Hitzenberger CK. Melanin Pigmentation in Rat Eyes: In Vivo Imaging by Polarization-Sensitive Optical Coherence Tomography and Comparison to Histology. Invest Ophthalmol Vis Sci 2015;56:7462-72.

50. Wilk MA, Huckenpahler AL, Collery RF, Link BA, Carroll J. The Effect of Retinal Melanin on Optical Coherence Tomography Images. Transl Vis Sci Technol 2017;6:8.

51. Lapierre-Landry M, Carroll J, Skala MC. Imaging retinal melanin: a review of current technologies. J Biol Eng 2018;12:29.

52. Chung YR, Lee SY, Kim YH, Byeon HE, Kim JH, Lee K. Hyperreflective foci in diabetic macular edema with serous 
retinal detachment: association with dyslipidemia. Acta Diabetol 2020;57:861-6.

53. Vujosevic S, Bini S, Torresin T, Berton M, Midena G, Parrozzani R, Martini F, Pucci P, Daniele AR, Cavarzeran F, Midena E. HYPERREFLECTIVE RETINAL SPOTS IN NORMAL AND DIABETIC EYES: B-Scan and En face Spectral Domain Optical Coherence Tomography Evaluation. Retina 2017;37:1092-103.

54. Vujosevic S, Torresin T, Berton M, Bini S, Convento E, Midena E. Diabetic Macular Edema With and Without Subfoveal Neuroretinal Detachment: Two Different Morphologic and Functional Entities. Am J Ophthalmol 2017;181:149-55.

55. Lujan BJ, Roorda A, Croskrey JA, Dubis AM, Cooper RF, Bayabo JK, Duncan JL, Antony BJ, Carroll J. Directional optical coherence tomography provides accurate outer nuclear layer and henle fiber layer measurements. Retina 2015;35:1511-20.

56. Lujan BJ, Roorda A, Knighton RW, Carroll J. Revealing Henle's fiber layer using spectral domain optical coherence tomography. Invest Ophthalmol Vis Sci 2011;52:1486-92.

57. Otani T, Yamaguchi Y, Kishi S. Improved visualization of Henle fiber layer by changing the measurement beam angle on optical coherence tomography. Retina 2011;31:497-501.

58. Boone MA, Suppa M, Dhaenens F, Miyamoto M, Marneffe A, Jemec GB, Del Marmol V, Nebosis R. In vivo assessment of optical properties of melanocytic skin lesions and differentiation of melanoma from non-malignant lesions by high-definition optical coherence tomography. Arch Dermatol Res 2016;308:7-20.

59. Tsai MR, Ho TS, Wu YH, Lu CW. In vivo dual-mode fullfield optical coherence tomography for differentiation of types of melanocytic nevi. J Biomed Opt 2021;26:020501.

60. Yiu G, Vuong VS, Oltjen S, Cunefare D, Farsiu S, Garzel L, Roberts J, Thomasy SM. Effect of Uveal Melanocytes on Choroidal Morphology in Rhesus Macaques and Humans on Enhanced-Depth Imaging Optical Coherence Tomography. Invest Ophthalmol Vis Sci 2016;57:5764-71.

Cite this article as: Kim $\mathrm{YH}$, Oh J. Comparison of choroidal hyperreflective spots on optical coherence tomography images between both eyes of normal subjects. Quant Imaging Med Surg 2022;12(2):920-935. doi: 10.21037/qims-21-637 


\section{Supplementary}

Table S1 The correlation of age with reflectivity of each choroidal slab and the distribution of hyperreflective spots

\begin{tabular}{|c|c|c|c|c|}
\hline & \multicolumn{2}{|c|}{ DRI OCT Triton } & \multicolumn{2}{|c|}{ PLEX Elite 9000} \\
\hline \multicolumn{5}{|c|}{ First choroidal layer } \\
\hline Reflectivity & -0.054 & 0.775 & -0.278 & 0.137 \\
\hline \multicolumn{5}{|c|}{ Hyperreflective spots } \\
\hline Total area & 0.169 & 0.372 & 0.350 & 0.058 \\
\hline \multicolumn{5}{|c|}{ Second choroidal layer } \\
\hline Reflectivity & -0.094 & 0.620 & 0.108 & 0.569 \\
\hline \multicolumn{5}{|c|}{ Hyperreflective spots } \\
\hline \multicolumn{5}{|c|}{ Third choroidal layer } \\
\hline Reflectivity & -0.472 & $0.008^{*}$ & 0.426 & 0.019 \\
\hline \multicolumn{5}{|c|}{ Hyperreflective spots } \\
\hline Number & -0.274 & 0.143 & 0.082 & 0.665 \\
\hline Total area & -0.510 & $0.004^{*}$ & 0.146 & 0.441 \\
\hline \multicolumn{5}{|c|}{ Fourth choroidal layer } \\
\hline Reflectivity & -0.582 & $0.001^{*}$ & 0.202 & 0.285 \\
\hline \multicolumn{5}{|c|}{ Hyperreflective spots } \\
\hline Number & -0.213 & 0.258 & -0.294 & 0.115 \\
\hline Total area & -0.410 & $0.025^{*}$ & -0.284 & 0.128 \\
\hline
\end{tabular}

*, $\mathrm{P}$ values using Spearman's correlation analysis were statistically significant at the $\mathrm{P}<0.05$ level. 
Table S2 The correlation of axial length with reflectivity of each choroidal slab and the distribution of hyperreflective spots

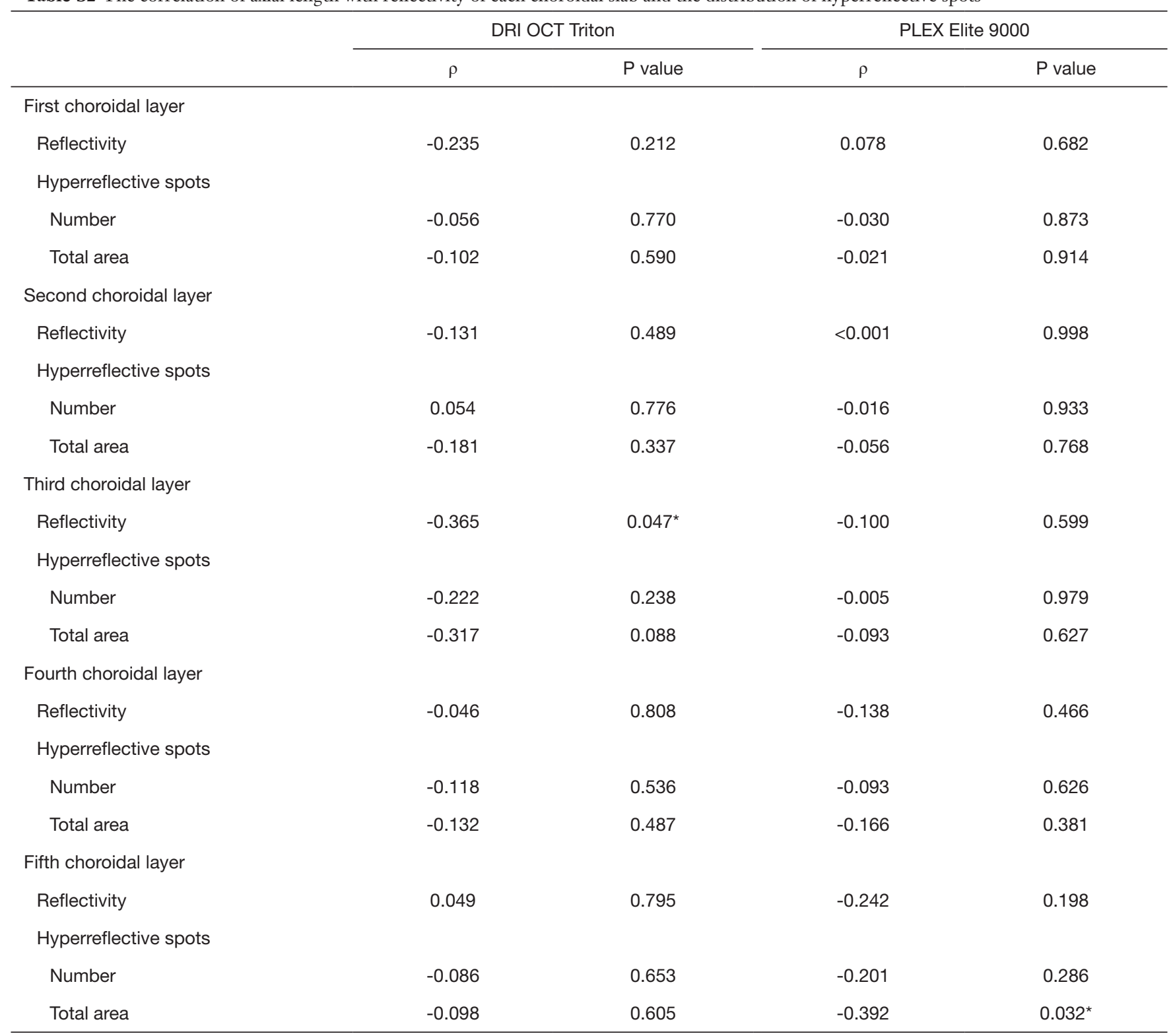

*, $\mathrm{P}$ values using Spearman's correlation analysis were statistically significant at the $\mathrm{P}<0.05$ level. 
Table S3 Post hoc multiple pairwise comparisons of reflectivity of the choroidal slab and distributions of hyperreflective spots between en face slab images obtained at five different depth positions of the upper choroid

\begin{tabular}{|c|c|c|c|c|c|c|c|c|c|c|c|}
\hline \multirow{3}{*}{$\begin{array}{l}\text { OCT } \\
\text { devices }\end{array}$} & \multirow{3}{*}{$\begin{array}{l}\text { Pairwise } \\
\text { comparisons }\end{array}$} & \multirow{2}{*}{\multicolumn{2}{|c|}{ Reflectivity }} & \multicolumn{8}{|c|}{ Hyperreflective spots } \\
\hline & & & & \multicolumn{2}{|c|}{ Number } & \multicolumn{2}{|c|}{ Total area } & \multicolumn{2}{|c|}{ Circularity } & \multicolumn{2}{|c|}{ Average Size } \\
\hline & & $\begin{array}{l}\text { Difference } \\
\text { in rank sum }\end{array}$ & P value & $\begin{array}{l}\text { Difference } \\
\text { in rank sum }\end{array}$ & $\mathrm{P}$ value & $\begin{array}{c}\text { Difference } \\
\text { in rank sum }\end{array}$ & P value & $\begin{array}{l}\text { Difference } \\
\text { in rank sum }\end{array}$ & $\mathrm{P}$ value & $\begin{array}{l}\text { Difference } \\
\text { in rank sum }\end{array}$ & $\mathrm{P}$ value \\
\hline \multirow{6}{*}{$\begin{array}{l}\text { DRI } \\
\text { OCT } \\
\text { Triton }\end{array}$} & 1st slab - 2nd slab & -90.0 & $<0.001^{*}$ & -63.5 & $<0.001^{*}$ & -78.0 & $<0.001^{*}$ & 57.5 & $<0.001^{*}$ & -91.0 & $<0.001^{*}$ \\
\hline & 1st slab - 3rd slab & -64.0 & $<0.001^{*}$ & -104.0 & $<0.001^{*}$ & -95.0 & $<0.001^{\star}$ & 44.5 & $0.003^{*}$ & -74.0 & $<0.001^{*}$ \\
\hline & 1st slab - 5th slab & -32.0 & 0.090 & -64.0 & $<0.001^{*}$ & -67.0 & $<0.001^{*}$ & 56.5 & $<0.001^{*}$ & -69.0 & $<0.001^{\star}$ \\
\hline & 2nd slab - 3rd slab & 26.0 & 0.338 & -40.0 & $0.011^{*}$ & -17.0 & $>0.999$ & -13.0 & $>0.999$ & 17.0 & $>0.999$ \\
\hline & 2nd slab - 4th slab & 46.0 & $0.002^{*}$ & -5.5 & $>0.999$ & 23.0 & 0.604 & -28.5 & 0.200 & 50.0 & $<0.001^{\star}$ \\
\hline & 4th slab - 5th slab & 12.0 & $>0.999$ & 5.0 & $>0.999$ & -12.0 & $>0.999$ & 27.5 & 0.247 & -28.0 & 0.222 \\
\hline \multirow{6}{*}{$\begin{array}{l}\text { PLEX } \\
\text { Elite } \\
9000\end{array}$} & 1st slab - 2nd slab & -19.0 & $>0.999$ & -13.5 & $>0.999$ & -17.0 & $>0.999$ & 24.0 & 0.500 & -29.0 & 0.179 \\
\hline & 1st slab - 3rd slab & -60.0 & $<0.001^{*}$ & -48.5 & $<0.001^{*}$ & -50.5 & $<0.001^{*}$ & 63.0 & $<0.001^{*}$ & -59.0 & $<0.001^{*}$ \\
\hline & 1st slab - 4th slab & -92.0 & $<0.001^{*}$ & -78.0 & $<0.001^{*}$ & -86.5 & $<0.001^{*}$ & 72.0 & $<0.001^{*}$ & -89.0 & $<0.001^{*}$ \\
\hline & 1st slab - 5th slab & -89.0 & $<0.001^{*}$ & -100.0 & $<0.001^{*}$ & -98.5 & $<0.001^{*}$ & 66.0 & $<0.001^{*}$ & -83.0 & $<0.001^{*}$ \\
\hline & 2nd slab - 3rd slab & -41.0 & $0.008^{\star}$ & -35.0 & $0.043^{*}$ & -33.5 & 0.062 & 39.0 & $0.015^{\star}$ & -30.0 & 0.143 \\
\hline & 2nd slab - 4th slab & -73.0 & $<0.001^{*}$ & -64.5 & $<0.001^{*}$ & -69.5 & $<0.001^{*}$ & 48.0 & $<0.001^{*}$ & -60.0 & $<0.001^{*}$ \\
\hline
\end{tabular}

${ }^{*}, \mathrm{P}$ values using Dunn-Bonferroni multiple comparison test were statistically significant at $\mathrm{P}<0.05$. 